\title{
Immuno-Interception of Human Chorionic Gonadotropin has Two Applications of Extraordinary Utility
}

\author{
Talwar GP* and Gupta Jagdish C \\ Talwar Research Foundation, E-8, Neb Valley, New Delhi-110068, India
}

ISSN: 2640-9666

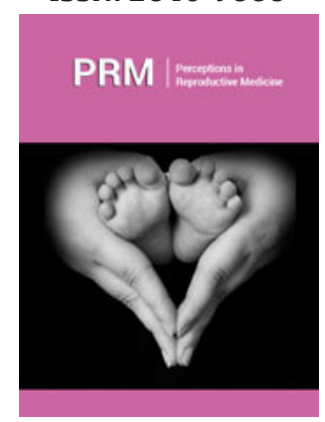

*Corresponding author: Talwar GP, Talwar Research Foundation, New Delhi-110068, India

Submission: 梅 July 03, 2019

Published: 监July 09, 2019

Volume 3 - Issue 3

How to cite this article: Talwar GP, Gupta Jagdish C. Immuno-Interception of $\mathrm{Hu}$ man Chorionic Gonadotropin has Two Applications of Extraordinary Utility. Perception in Reproductive Medicine.3(3) PRM.000565.2019.

DOI: 10.31031/PRM.2019.03.000565

Copyright@ Talwar GP, This article is distributed under the terms of the Creative Commons Attribution 4.0 International License, which permits unrestricted use and redistribution provided that the original author and source are credited.

\section{Opinion}

We reported in 1994, the ability of a vaccine developed against hCG to prevent pregnancy in sexually active women of proven fertility [1]. Only one pregnancy took place in 1224 cycles. Eight women completed 30 cycles without becoming pregnant, nine were protected over 2429 cycles, 12 for $18-23$ cycles, 15 for $12-17$ cycles and 21 for $6-11$ cycles. All women continued to ovulate as was evident from luteal phase progesterone. They continued to have regular Menstrual cycles. This vaccine has now been converted to a genetically engineered vaccine so that it is amenable to industrial production. Figure 1 shows the design of the vaccine which consists of hCG $\beta$ linked to B chain of heat-labile enterotoxin of E. coli, as carrier [2]. The vaccine has been passed onto M/s Bharat Biotech, who will make the vaccine under GMP conditions. A new round of clinical trial will be carried out on the recombinant vaccine to prove its safety and efficacy. Approval has been received from the Drugs Controller General of India and Institutional Ethics Committees to conduct these trials at the All India Institute of Medical Sciences and Sir Gangaram Hospital New Delhi. A new feature of this vaccine will be the use of both the DNA and protein form of the vaccine. Initial priming with 2 injections of the DNA form of the vaccine at zero and $15^{\text {th }}$ day followed by the $3^{\text {rd }}$ and $4^{\text {th }}$ injections given on day 30 and 45 with the Protein form of the vaccine, raises considerably the quantum of antibody response.

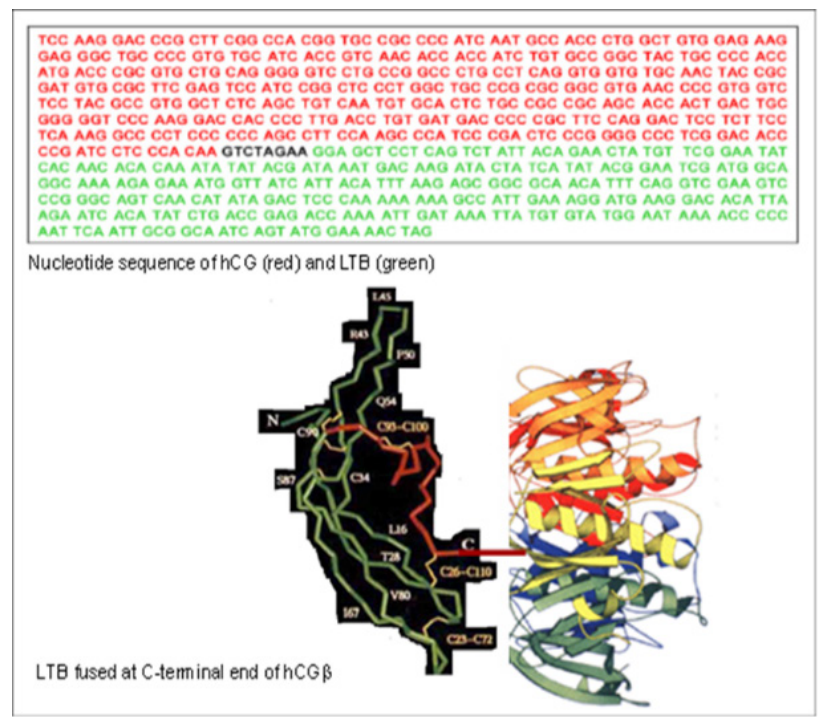

Figure 1: Conceptualized structure of hCG $\beta$-LTB vaccine. The carrier $B$ chain of heat labile enterotoxin of $\mathrm{E}$. coli (LT $\beta$ ) is fused at C-terminal glutamine of hCG $\beta$.

The previously reported vaccine heralded the encouraging possibility of birth control without any derangement of ovulation, hormonal profiles and menstrual regularity. Let us hope that the genetically engineered version of the same vaccine retains the same properties. 
Another highly interesting and useful application of the anti-hCG vaccine is expected for treatment of advanced stage invariably drugsresistant cancers expressing ectopically hCG. HCG or its subunits have been reported to be expressed in a variety of nontrophoblastic cancers such as lung cancer [3], bladder carcinoma [4], colorectal carcinoma [5], pancreatic carcinoma [6], breast cancer [7], cervical carcinoma [8], oral cancers [9], vulva/vaginal cancers [10], prostate cancer [11] and gastric carcinomas [12]. The rationale behind the utility of the anti-hCG vaccine in treatment of hCG positive cancers lies in our observations that PiPP, a monoclonal antibody developed against hCG, kills such cancers. Given below are the observations on A549 lung cancer cell line. While FACS analysis showed that nearly 99\% of the cells express hCG, incubation with different dilutions of monoclonal antibody PiPP in the presence of complement, 96\% of A549 cancer cells were killed (Figure 2). While many cancers expressing hCG are killed by the antibody directly in the presence of complement, some cancer cells, such as Molt4 T-lymphoblastic leukemia cells, though expressing hCG, are not killed by the antibody. However, if a conjugate of PiPP with curcumin is employed, it is effective in killing these cancer cells (Figure 3).

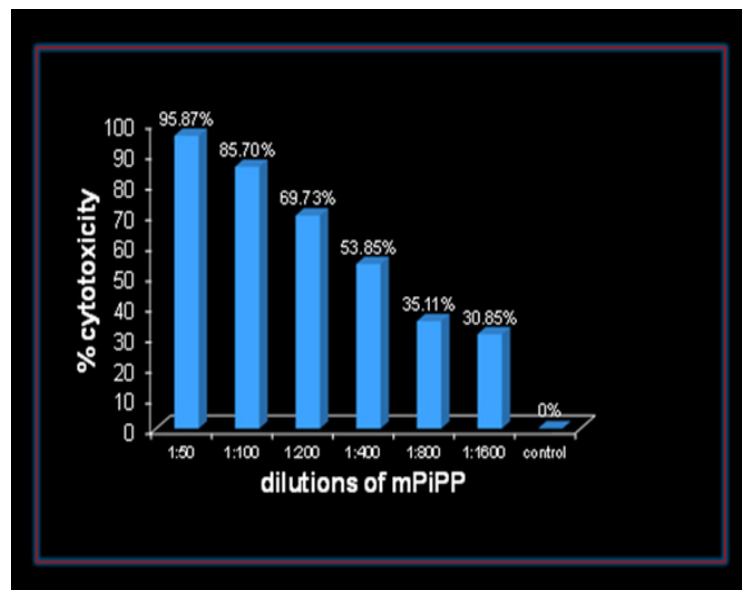

Figure 2: Dose dependent cytotoxicity exercised by the monoclonal anti-hCG-antibody PiPP on Lung Cancer cells (A549).

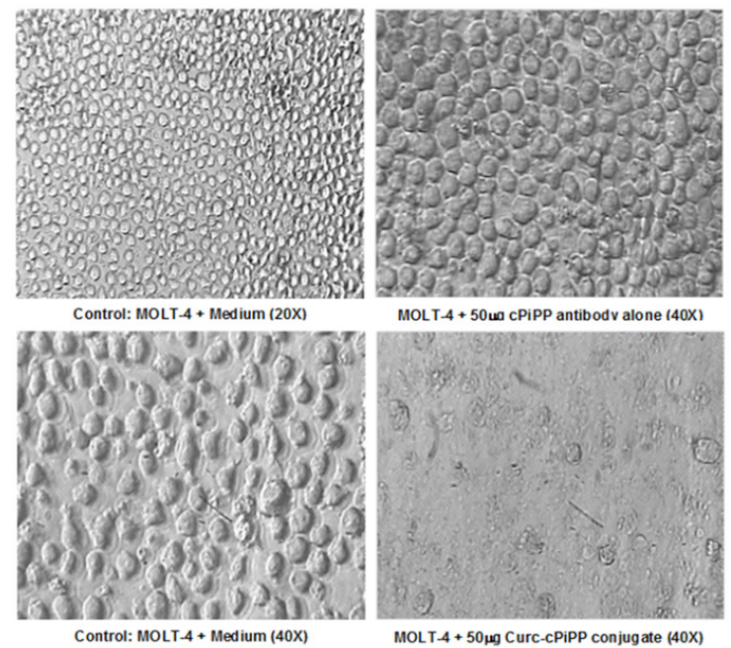

Figure 3: Photomicrograph of MOLT-4 cells after incubation with mouse monoclonal PiPP alone and PiPPcurcumin conjugate. Cells incubated in culture medium are used as control.

\section{Acknowledgement}

The clinical trial on the recombinant hCG vaccine is supported by a grant from the Indian council of Medical Research.

\section{References}

1. Talwar GP, Singh O, Pal R, Chatterjee N, Sahai P, et al. (1994) A vaccine that prevents pregnancy in women. Proc Natl Acad Sci USA 91(18): 8532-8536.

2. Purswani S, Talwar GP (2011) Development of a highly immunogenic recombinant candidate vaccine against human chorionic gonadotropin. Vaccine 29(12): 2341-2348.

3. Dirnhofer S, Freund M, Rogatsch H, Krabichler S, Berger P (2000) Selective expression of trophoblastic hormones by lung carcinoma: neuroendocrine tumors exclusively produce human chorionic gonadotropin $\alpha$-subunit (hCG $\alpha$ ). Hum Pathol 31(8): 966-972.

4. Dirnhofer S, Koessler P, Ensinger C, Feichtinger H, Madersbacher S, et al. (1998) Production of trophoblastic hormones by transitional cell carcinoma of the bladder: Association to tumor stage and grade. Hum Pathol 29: 377-382. 
5. Louhimo J, Holmstrom CM, Alfthan H, Stenman UH, Jarvinen HJ, et al (2002) Serum hCG b, CA 72-4 and CEA are independent prognostic factors in colorectal cancer. Int J Cancer 101: 545-548.

6. Syrigos KN, Fyssas I, Konstandoulakis MM, Harrington KJ, Papadopoulos $\mathrm{S}$, et al. (1998) Beta human chorionic gonadotropin concentrations in serum of patients with pancreatic adenocarcinoma. Gut 42(1): 88-91.

7. Agnantis NJ, Patra F, Khaldi L, Filis S (1992) Immunohistochemical expression of subunit $\beta$ HCG in breast cancer. Eur J Gynaecol Oncol 13(6): 461-466.

8. Crawford RA, Iles RK, Carter PG, Caldwell CJ, Shepherd JH, et al. (1998) The prognostic significance of beta human chorionic gonadotrophin and its metabolites in women with cervical carcinoma. J Clin Pathol 51(9): 685-688.
9. Hedstrom J, Grenman R, Ramsey H, Finne P, Lundin J, et al. (1999) Concentration of free hCG $\beta$ subunit in serum as a prognostic marker for squamous-cell carcinoma of the oral cavity and oropharynx. Int J Cancer 84(5): 525-528.

10. De Bruijn HW, Ten Hoor KA, Krans M, Vander Zee AG (1997) Rising serum values of $\beta$-subunit human chorionic gonadotrophin (hCG) in patients with progressive vulvar carcinomas. Br J Cancer 75: 1217-1218.

11. Sheaff MT, Martin JE, Badenoch DF, Baithun SI (1996) Beta hCG as a prognostic marker in adenocarcinoma of the prostate. J Clin Pathol 49(4): 329-332.

12. Zhang W, Yang H, Han S (1998) The effect of ectopic HCG on microvessel density in gastric carcinoma. Chin J Oncol 20(5): 351-353.

For possible submissions Click below: 